\title{
11
}

\section{COMPOSTING FOR SUSTAINABLE DEVELOPMENT IN A BALTIC SEA REGION PERSPECTIVE}

Anders Byström

RONDECOt $A B$

Sweden

\section{THE BALANCE IS DISTURBED}

The Baltic is today a polluted inland sea. Every day we are informed from different countries around the Baltic about discharge of unwanted substances which are devastating for flora and fauna in the water. It is not until the last one hundred years that this development has accelerated. During the growth of the industrialism the big scale use of the resources of the earth has disturbed the balance of the natural eco system. The streams of material and the use of energy make use of fossil energy and minerals to an extend that brakes the eco cycle. Nature can not re-create resources to the necessary extend.

There are several reasons for this unwanted development. The population growth, the need of consumption and the need of energy is how professor Paul Ehrlich sums it up. The unwanted and very large immigration to the cities is another reason. This development demands a very effective production in farming and as a consequence of this the farmers have started to use mechanical devices and chemical fertiliser. This has created an enormous flow of products from the countryside to the cities using transportation systems which cause chaos in the infra structure and also cause unacceptable emissions.

\section{GNP IS NOT ENOUGH}

Society has a difficulty in catching up with the development of technology, information and rules when trying to work against these unwanted environmental consequences of the trends. The economic incentives are also dragging along very slowly. The GNP (Gross National Product) is used for measuring the development of a country, but it does not take into consideration the perspective of 
the benefit of a total national economy. For instance, the GNP does not take into consideration the consumption of natural resources or the fulfilment of men's need. The GNP does not take into consideration anything that has not got a price on it. Technical development, expanding knowledge concerning relations and connections and also understandable information are necessary elements in the future. But also the questions conceming taxes, laws, more rigorous justice and penalties are in my opinion necessary to pay attention to.

\section{ORGANIC FERTILISER}

I will tell you about a very hopeful technical development in the field of organic fertiliser. Since 1970 The Innovation Institute in Stockholm and its research scientists has developed a process for drying compost and for pressing the compost together to pellets. These pellets have then been used in several big scale practical experiments both in agriculture and forestry with very good results.

Compost is a living thing. The aerobic microbes work continuously when they have access to air and water. If the compost lies intact some nutritious substances, most of all nitrogen, will be lost. At the end all of the nutritions has gone. The compost even sometimes gives away a bad smell. Therefore the compost must be used as soon as possible after being ready or mature, which will take about six weeks when processed in an effective way. Due to that, the compost itself is a less advisable fertiliser as you will lose different nutritious substances when storing it.

\section{COMPLICATED INTERACTION}

The task of the scientists was to "calm" the microbiological process without killing the microbes. The scientists succeeded and the pellets they developed from compost are suited for storing, easy to transport and very suitable as fertiliser. You can produce the pellets the year around and spread it when it is needed. When these pellets are brought to the soil, the root system of the plants creates a complicated interaction with the nutritious substances of the pellets. The microbes start their process and the nutrition will release, being effective for the root of the plant. This process comes to a standstill in the autumn when the plant has satisfied its need of nutrition. At the beginning of the next season the process will start again and the nutrition starts flowing to the root of the plant.

We have by practical experiments in our climate zone noticed that the pellets give away their nutrition gradually during 6-7 years. When there is no nutrition left there remains a humus product. By using organic fertiliser pellets on one hand the soil will get back nutrition in the pace the plants need it, and on the other hand the soil will get back the vitally important humus. In contrast to chemical fertiliser the organic fertiliser pellets do not leach to the surrounding soil or water streams. 


\section{THE RAW MATERIALS}

The raw materials for this organic fertiliser are municipal solid waste (MSW) and sewage sludge. Two of the big problems in society to day. The immigration to the cities creates unacceptable mountains of waste which on the whole is transported to a landfill. These landfills are ticking bombs as the microbes work there all the time, however in an uncontrolled way. Poisonous gas is blended with methane gas and is emitted to the surrounding air. Poisonous metals are dissolved and transported to our ground water. The volume needed for taking care of all the waste is very big and sometimes these landfills start burning which causes dangerous emissions to the air which will harm men and nature.

\section{THE AMOUNT OF MUNICIPAL SOLID WASTE}

The countries around the Baltic produces roughly the following amounts of municipal solid waste:

\begin{tabular}{|l|r|c|}
\hline Finland & 1500000 & tons per year \\
\hline Estonia & 450000 & tons per year \\
\hline Latvia & 870000 & tons per year \\
\hline Lithuania & 1140000 & tons per year \\
\hline Poland & 11400000 & tons per year \\
\hline Germany & 24000000 & tons per year \\
\hline Sweden & 3000000 & tons per year \\
\hline S:t Petersburg & 1500000 & tons per year \\
\hline Total & $\mathbf{4 3 8 6 0 0 0 0}$ & tons per year \\
\hline
\end{tabular}

Generally speaking about $75 \%$ of our municipal solid waste is organic and possible to compost. Treated in a correct way this $75 \%$ contains a great value. Also an economic value.

\section{QUALITY CONTROL}

When composting municipal solid waste and sewage sludge there must be a control of the incoming material. Ignorance, carelessness and obvious misuse of the system often make the MSW not clean enough. Especially the hazardous refuse cause problems, but also metals, textiles and some plastic materials. Unwanted substances in the sewage sludge make it difficult to use. But if you first carefully study the content of the MSW and the sludge, it is now possible to build a system that is adapted to this content and to take care of the organic fraction of our MSW and sludge from the sewage-treatment plant. 
We have discovered what gives the MSW a bad quality and can for instance as a first step change the routes of the lorries that collect the MSW. If you do not mix MSW with waste from for instance petrol stations you can avoid lowering the quality of the waste. Hazardous refuse must not be added but the process can handle insufficient source separation. By using the knowledge of the mineral industry in finding metals we can clean the compost and make a final quality control in the composting plant. Lead, which is a common heavy metal, can in this way be reduced by $80 \%$. It is also essential to treat the material in a careful way. The composting method itself can also deteriorate the material if you are not careful enough.

Since no grinding or shredding is used in the process, non-biodegradable materials come through the digester intact. Using mechanical devices ferrous metals, aluminium and plastic are recovered for re-use and recycling. After sorting there only remains a small fraction which needs to be landfilled. This considerably prolongs the life of the landfills. What ends up in the landfill is sanitised and does not pose any problems in terms of gas emissions, leakage and vermin.

\section{COMBINATIONS OF EXPERIENCES}

By combining experiences from composting with the experiences from pelletising you can create something valuable out of something that is as unpleasant as MSW and sewage sludge. By using today's technology and knowledge together with people's ambition to source separate the MSW, we can today produce an organic fertiliser which contents nutrition that can well match the chemical fertiliser. If requested nutrition can be added to the compost before pelletising. These possibilities can be used in countries around the Baltic and will then contribute towards a change for the better of the emission problem. Nutrition and humus that was taken from the farming land can be brought back from the cities as organic fertiliser pellets.

\section{THE HELSINKI CONVENTION}

Producing compost and organic fertiliser pellets from city solid waste and sewage sludge responds to several recommendations of the Helcom recommendations. Article 13/9 is about the need of reducing the leaching of nitrogen from farming. It is said that it is necessary to store manure from animals - a problem that is not so easy to solve. By treating the manure in a composting facility you will produce excellent organic fertiliser that is suited for storing.

Article $9 / 3$ is about reducing nutritious substances from farming land. Also hear composting can be an effective way to bring back nutrition to the soil. Article $13 / 10$ is about the need of reducing leaching of phosphorus and the question of erosion. By producing compost from MSW and sludge most of the need of phosphorus can be supplied for. Humus improves the ability of the soil to keep the moisture and it also prevents erosion. 


\section{ECONOMY}

Waste treatment costs money. In some countries around the Baltic the household pay the whole cost for the treatment. In other countries the trend has not come that far. The organic fertiliser may contribute to a faster change in waste treatment, as the product has an economic value. The basis of the value is the cost of the chemical fertiliser.

\section{FUTURE}

Accordingly, by speeding up the knowledge and information about organic fertiliser, society can speed up the solution of the waste treatment. For once, politicians in the countries around the Baltic can be united in actions that are consistent with the agreement that was signed in Helsinki in 1974, The Convention on the Protection of the Marine Environment of the Baltic Sea. 